\title{
Incorporation of text recognition into trial it systems to safeguard against enrolment of ineligible patients or inappropriate reporting of adverse events
}

\author{
Martin Dennis*, Rustam Salman, Gillian Mead, Connor McGill, David Perry \\ From 2nd Clinical Trials Methodology Conference: Methodology Matters \\ Edinburgh, UK. 18-19 November 2013
}

In the on-going multicentre FOCUS (http://www.focustrial. org.uk) and RESTART (http://www.RESTARTtrial.org) trials, researchers randomise patients and report adverse events via our bespoke web-based trial IT system.

Our protocols specify certain medical conditions, and concurrent medications, which make the patient ineligible e.g. epilepsy, anticoagulants. As well as asking the researchers to answer questions to confirm the presence or absence of particular criteria, we have also introduced text recognition as an added safeguard. For example, if when the researcher enters the list of patients' concurrent medications, they enter a drug which is incompatible with the IMP, then the text recognition system highlights this. Epilepsy is a contraindication in the FOCUS trial, so that if the researcher enters the name of any anticonvulsant drug, the system highlights the potential ineligibility.

Our protocols have identified certain adverse events (AEs) e.g. stroke, or heart attack, which may occur during follow-up and which should be reported as "outcomes" rather than via the $\mathrm{AE}$ reporting system. Also, to minimise the burden on researchers we have identified AEs which are common complications of the index disease or IMP, which don't need to be reported as an AE. If a researcher enters a term, for example "stroke" or "epilepsy", then our text recognition highlights this and the system recommends the more appropriate course of action. This aims to avoid inappropriate reporting of AEs with the attendant need for these to be reported to the sponsor and also followed up to resolution etc.

Published: 29 November 2013

University of Edinburgh, Edinburgh, UK

C 2013 Dennis et al; licensee BioMed Central Ltd. This is an Open Access article distributed under the terms of the Creative Commons Attribution License (http://creativecommons.org/licenses/by/2.0), which permits unrestricted use, distribution, and reproduction in any medium, provided the original work is properly cited.
doi:10.1186/1745-6215-14-S1-015

Cite this article as: Dennis et al: Incorporation of text recognition into trial it systems to safeguard against enrolment of ineligible patients or inappropriate reporting of adverse events. Trials 2013 14(Suppl 1):015.

Submit your next manuscript to BioMed Central and take full advantage of:

- Convenient online submission

- Thorough peer review

- No space constraints or color figure charges

- Immediate publication on acceptance

- Inclusion in PubMed, CAS, Scopus and Google Scholar

- Research which is freely available for redistribution

Submit your manuscript at

C Biomed Central 